Research Article

\title{
Experimental Investigation of the Anomalously Low Friction Phenomena in Blocky Rock Systems
}

\author{
Yehui Shi, ${ }^{1}$ Hao Lu $\left(\mathbb{D},{ }^{2}\right.$ Shuxin Deng, ${ }^{3}$ Chenghua $X u,{ }^{1}$ and Helan Cheng ${ }^{1}$ \\ ${ }^{1}$ Tunnel and Underground Engineering Research Center of Jiangsu Province (TERC), Nanjing 210041, China \\ ${ }^{2}$ State Key Laboratory of Disaster Prevention and Mitigation of Explosion and Impact, The Army Engineering University of PLA, \\ Nanjing 210094, China \\ ${ }^{3}$ School of Mechanical Engineering, Nanjing University of Science and Technology, Nanjing 210094, China \\ Correspondence should be addressed to Hao Lu; 465576221@qq.com
}

Received 9 August 2020; Accepted 12 September 2020; Published 10 October 2020

Academic Editor: Peixin Shi

Copyright (C) 2020 Yehui Shi et al. This is an open access article distributed under the Creative Commons Attribution License, which permits unrestricted use, distribution, and reproduction in any medium, provided the original work is properly cited.

\begin{abstract}
Rock masses can be regarded as a blocky rock system. After a disturbance load is applied, the anomalously low friction phenomenon may take place and cause geological disasters. A series of impact experiments on granite blocks were conducted to investigate the anomalously low friction phenomena. Vertical vibration, Fourier frequency spectrum, and horizontal motions were investigated. It can be found that the tensile phases of vertical vibration can reduce the maximum static friction force, namely, the shear strength. The quasi-resonance operating mode of the rock blocks was observed. During the stress wave propagation, the vibration in the loading direction tends to transfer from high frequency to low frequency and the modes of stress wave propagation do not depend on disturbance energies. The observed translational and rotational motions were due to the initial shear force, which is less than the friction force with no disturbance load. Stability of the blocky rock system is very sensitive to the initial stress state. In the subcritical state, friction force reduction can easily break the equilibrium of forces along the contact surface and even a slight disturbance may make the horizontal motions happen, which may lead to geological disasters with great energy release.
\end{abstract}

\section{Introduction}

When an external disturbance load is applied on rock masses, friction between adjacent rock blocks in the orthogonal direction to the disturbance load may be significantly reduced or even completely disappeared, which is known as an anomalously low friction phenomenon $[1,2]$. The phenomenon may lead to serious geological disasters, such as the large-scope tunnel deformations [3-5] and sliptype rock bursts [6-8] in the surrounding rock masses around tunnels. These disturbance-induced geological disasters can pose considerable threats to construction safety and the stability of underground engineering.

Natural rock masses can be considered as assemblies of rock blocks of different sizes [9-11]. The generalized faults between adjacent rock blocks can involve quite a wide range of scale levels from microscopic scale levels to macroscopic scale levels. Effective strengths of these faults are much lower than the rock blocks, which makes the faults turn into slip surfaces. And the effective strengths will be further reduced due to the anomalously low friction phenomena after external disturbances, which can be caused by a nearby blasting [4, 12], a construction disturbance $[13,14]$, an earthquake $[15,16]$, and so on.

A simple rock block model as shown in Figure 1 is taken to analyse the geological disasters induced by the anomalously low friction phenomena $[2,17,18]$. Kurlenya et al. $[19,20]$ studied the anomalously low friction phenomena in block media from various geomaterials and found that significant displacements of the working blocks occur at absolute values of plus actions, which are much smaller than the corresponding friction forces. Kocharyan et al. [21] utilized drop-weight apparatuses to apply disturbance forces and investigate the dynamic response of a blocky system. It 


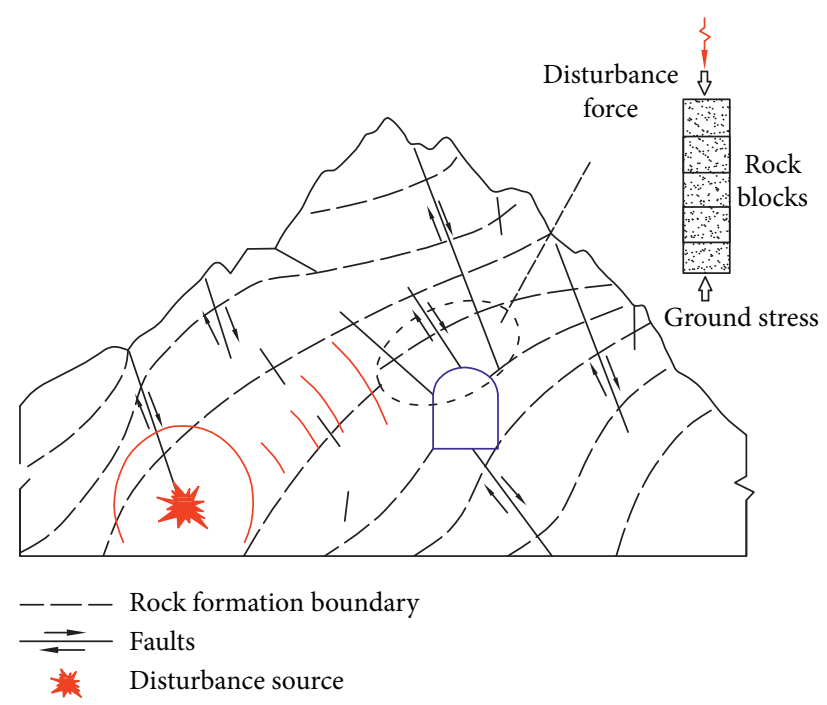

Figure 1: Schematic diagram of disturbance-induced geological disasters.

was not conducive for precise control of the loading process. Moreover, the displacements in the loading direction were difficult to obtain using superimposed blocky model in prior experimental studies $[18,21,22]$. In the present paper, we used an electrodynamic vibration exciter to provide the shock loading and a digital image correlation (DIC) method based on high-speed photography to perform quantitative in-plane deformation measurement. Under vertical impact disturbance loads, the anomalously low friction phenomena were investigated. Vertical vibration, Fourier frequency spectrum, and horizontal motion were obtained. The mechanism of the disturbance-induced residual displacements and rock bursts due to the anomalously low friction phenomena was discussed.

\section{Experimental Methods}

2.1. Experimental Model. Experimental system is depicted in Figure 2. All the five granite blocks were cut from an intact rock. The dimensions of these rock blocks are $160 \mathrm{~mm} \times 125 \mathrm{~mm} \times 125 \mathrm{~mm}$. Mass of a single granite block is $6.8 \mathrm{~kg}$. $P$-wave velocity $C_{\mathrm{p}}$ is $4300 \mathrm{~m} / \mathrm{s}$. Density of the granite is $\rho=2720 \mathrm{~kg} / \mathrm{m}^{3}$. The rock blocks stacked vertically (see Figure 2(b)) and marked 1 to 5 from top to bottom.

2.2. Loading System. As plotted in Figure 2(a), an electrodynamic vibration exciter, including a flexible stinger and a force transducer, is fixed upon the top block to provide vertical disturbance forces. The electrodynamic vibration exciter can convert electrical energy into impact energy to provide precise and controllable excitation force of amplitude up to $1000 \mathrm{~N}$. With the load delay control system to accurately control the impact load start time, the exciter can achieve accurate adjustment of $0-200 \mathrm{~ms}$ at any time interval. The stinger transmits force in the stiff axial direction and flexes laterally to reduce input side loads to the top rock block. This uniaxial force delivered by the flexible stinger increases the accuracy of the measurement. The force transducer along with the exciter can measure the input forces applied to the block system. Figure 3 shows the timehistory curves of vertical disturbance force $p(t)$. Upon calucation, the integral of $p(t)$ and the impulse $I$ can be obtained as

$$
I=\int_{0}^{\infty} p(t) \mathrm{d} t .
$$

Initial velocity of the top rock block is assumed to be 0 , and the duration is considered to be extremely short (see Figure 3). Thus, the disturbance energy $W$ can be expressed as follows:

$$
W=\frac{1}{2 m}\left|\int_{0}^{\infty} p(t) \mathrm{d} t\right|^{2}=\frac{I^{2}}{2 m},
$$

where $p(t)$ is the time-history function of the disturbing force and $m$ is the mass of a single block.

2.3. Measuring System. Digital image correlation (DIC) method is a noncontact and full-field measurement technique [23], which is very suitable to obtain full-field displacement and strains. Due to extremely relaxed environmental requirements, DIC method is widely applied during mechanical experiments [24]. A high-speed camera is often used to capture high-resolution digital images at ultrahigh speeds, which can provide a better observation and understanding previously invisible processes and phenomena. In our experiments, a PHOTRON FASTCAM SA-Z High-Speed Camera, with a maximum frame rate of $20,000 \mathrm{fps}$ and a maximum resolution of $1024 \times 1024$ pixels, was used to record the motions of the block system. As shown in Figure 2(c), two LED lights were used for easy pixel capture. Images with $1024 \times 512$ pixels taken at $1000 \mathrm{fps}$ were obtained. After recording the 


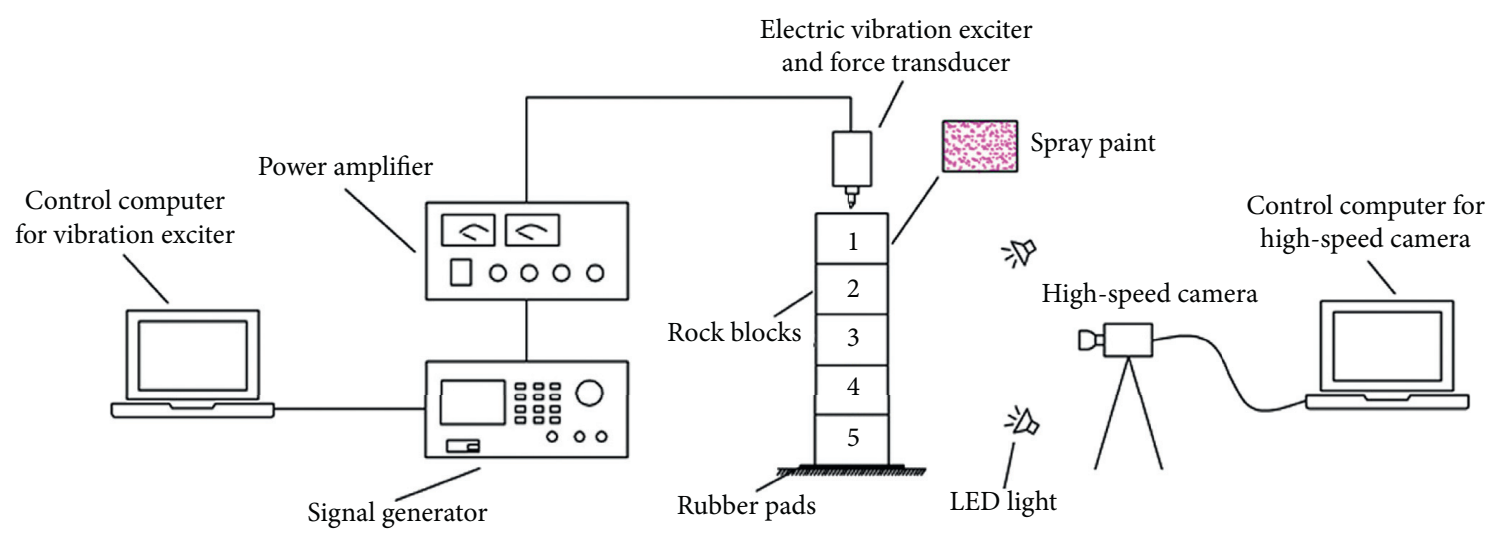

(a)
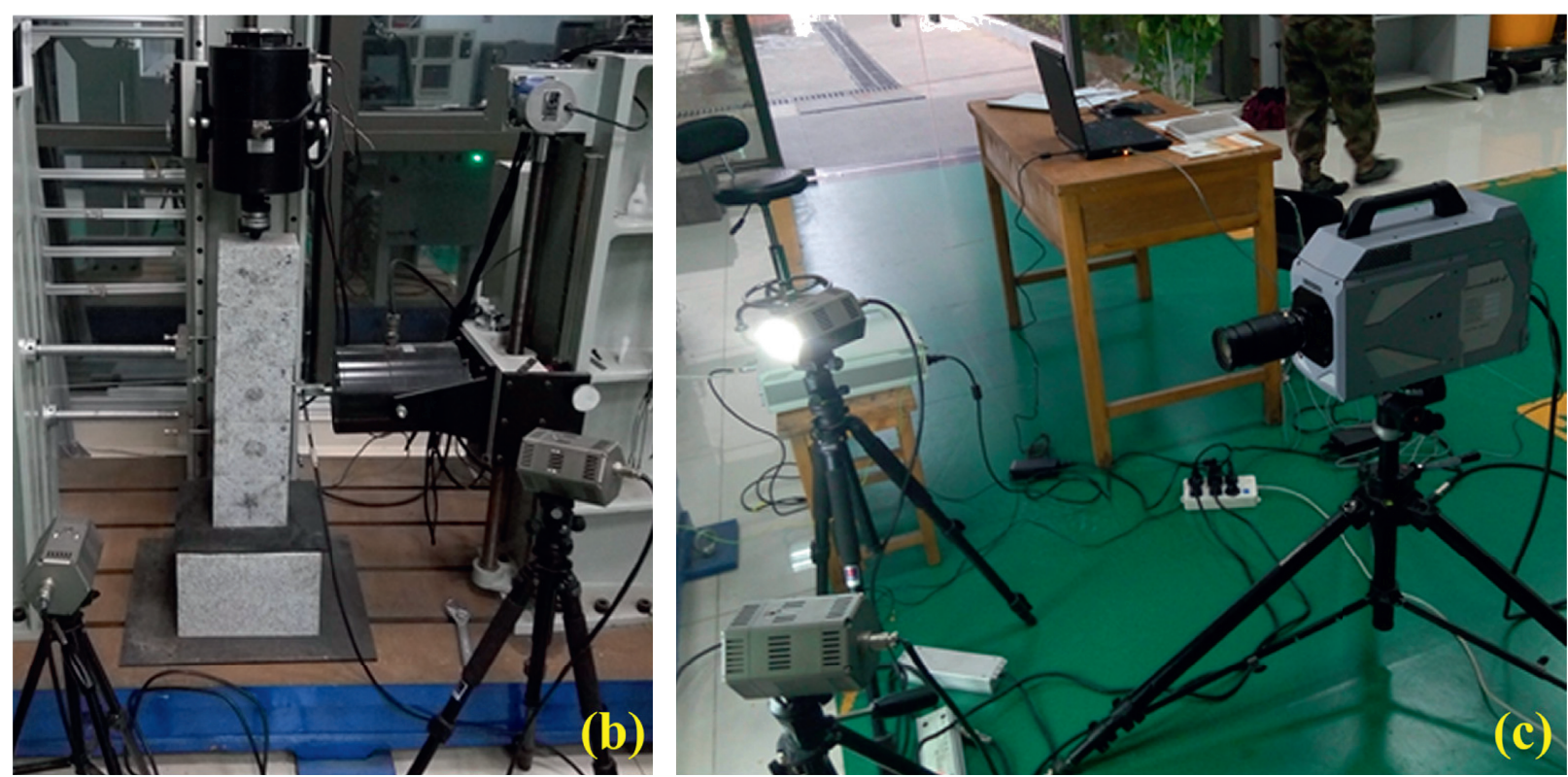

FIGURE 2: Experiment apparatus: (a) schematic diagram; (b) photograph of rock blocks; (c) photograph of DIC measurement system.

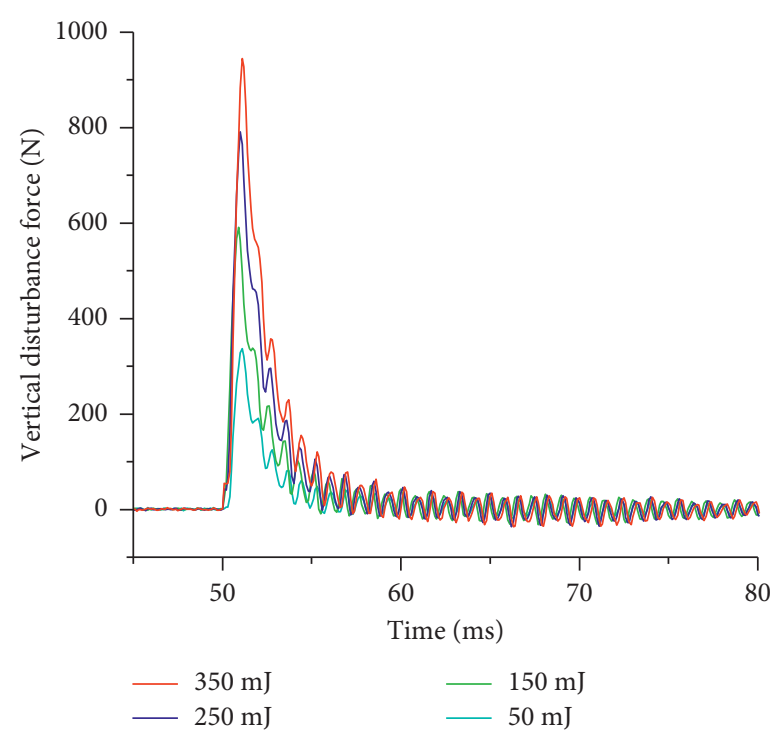

FIgURE 3: Time-history curves of vertical disturbance force with different disturbance energies. 


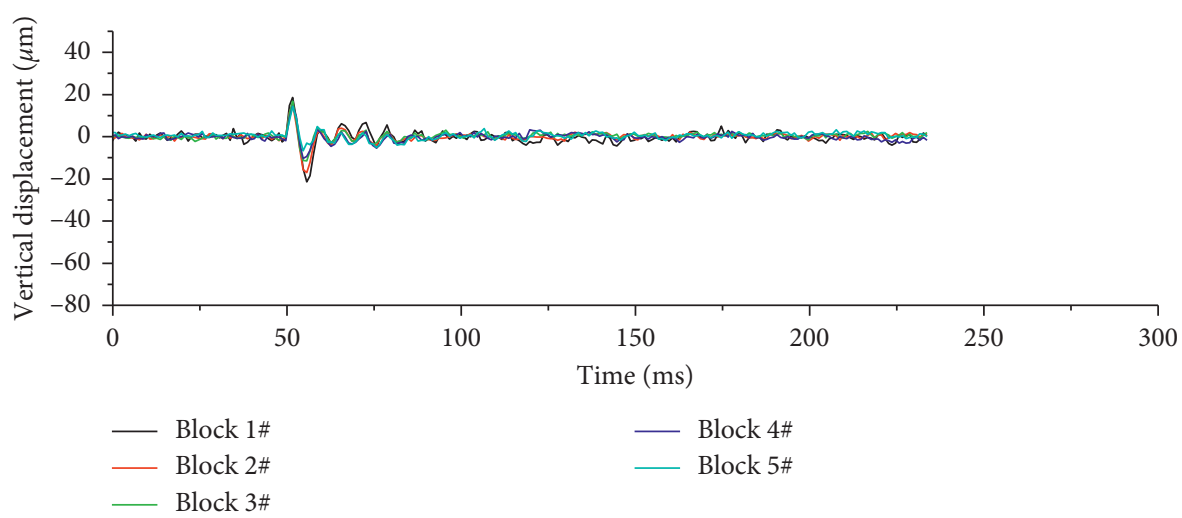

(a)
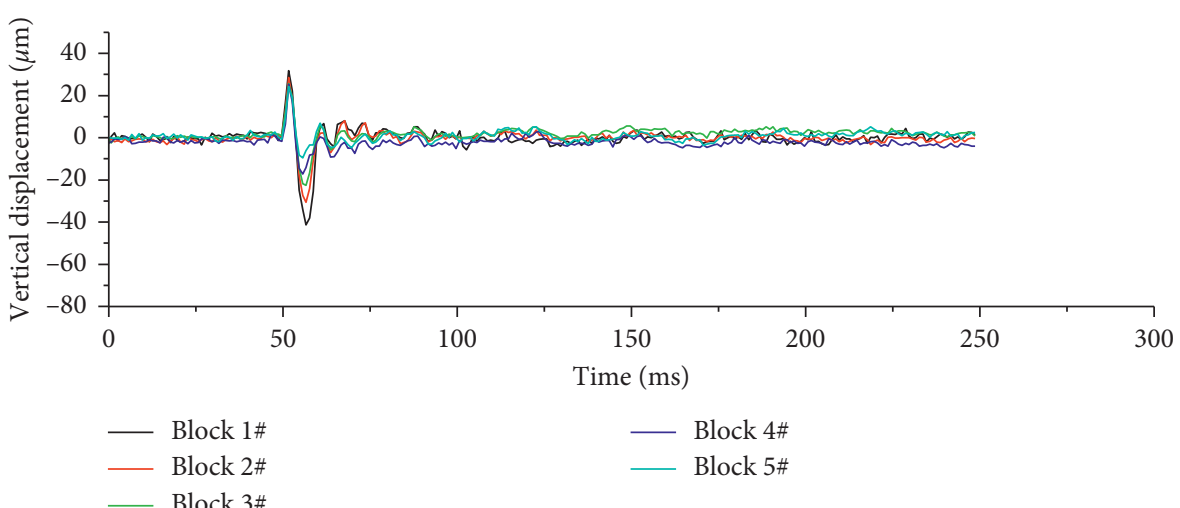

(b)

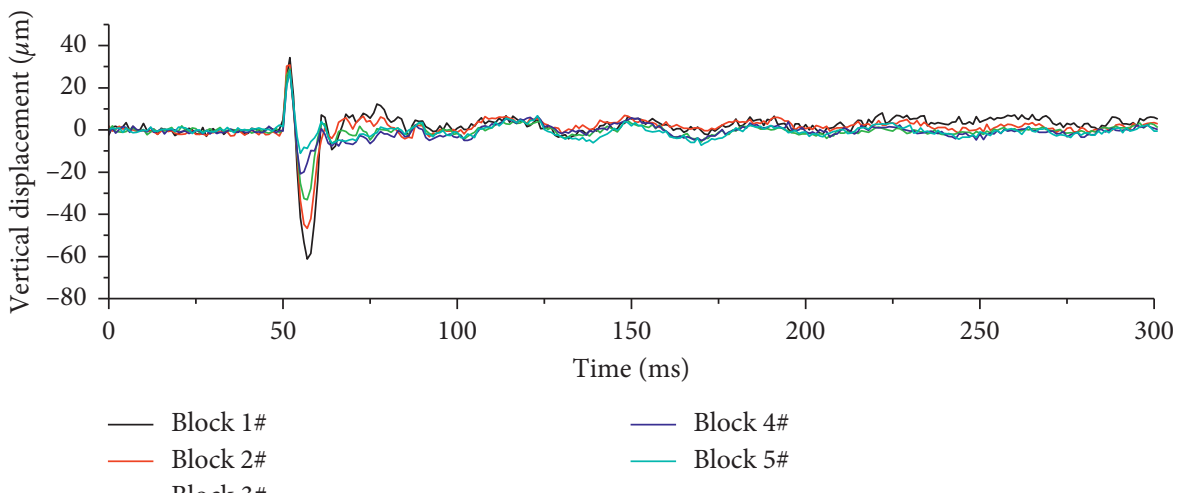

(c)

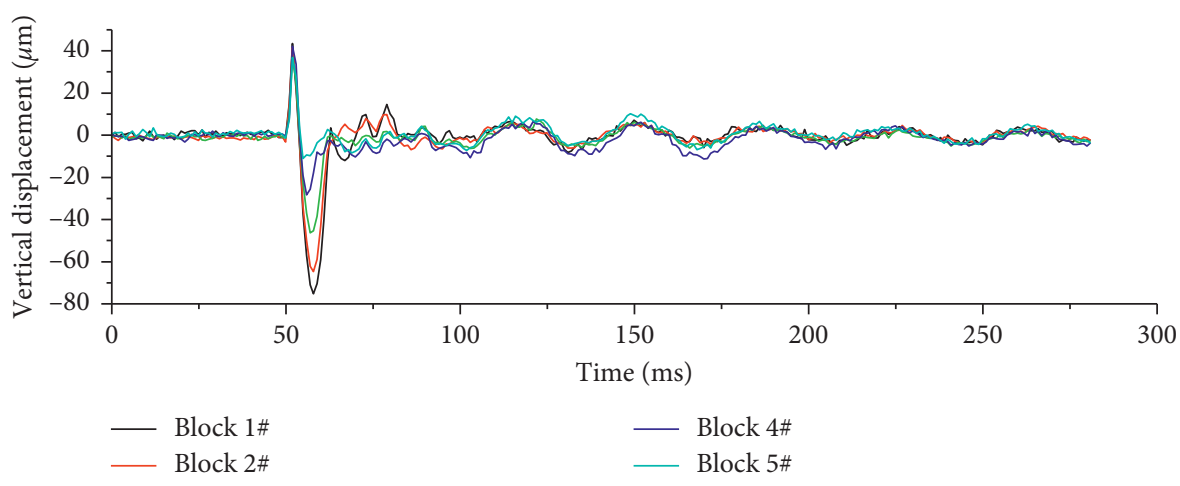

(d)

FIGURE 4: Vertical displacements of rock blocks with different disturbance energies: (a) $50 \mathrm{~mJ}$; (b) $150 \mathrm{~mJ}$; (c) $250 \mathrm{~mJ}$; (d) $300 \mathrm{~mJ}$. Positive values indicate the compression displacements, while negative ones do the opposite. 


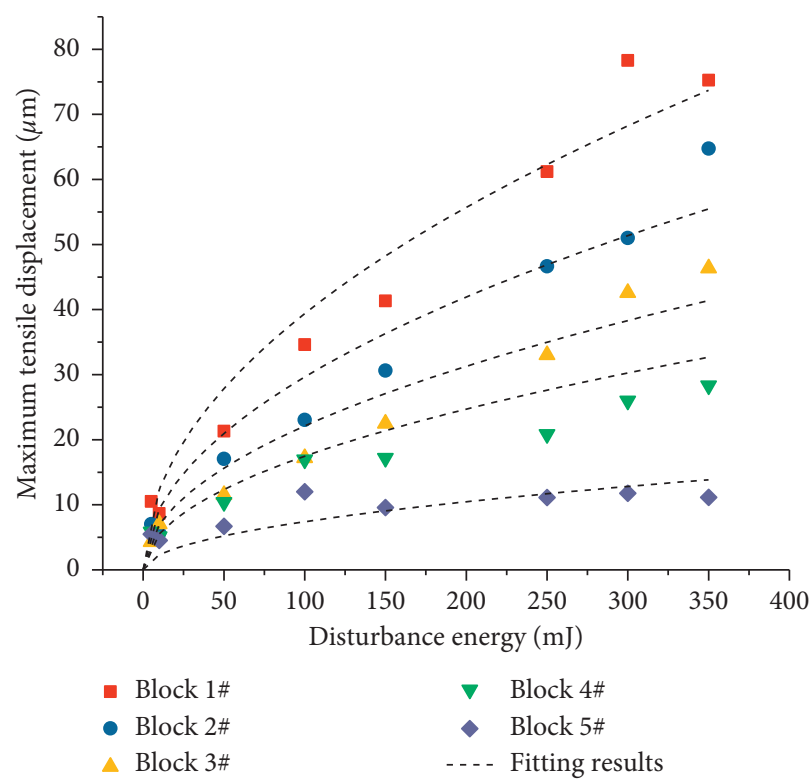

FIGURE 5: Relations between the maximum tensile displacements and disturbance energies.

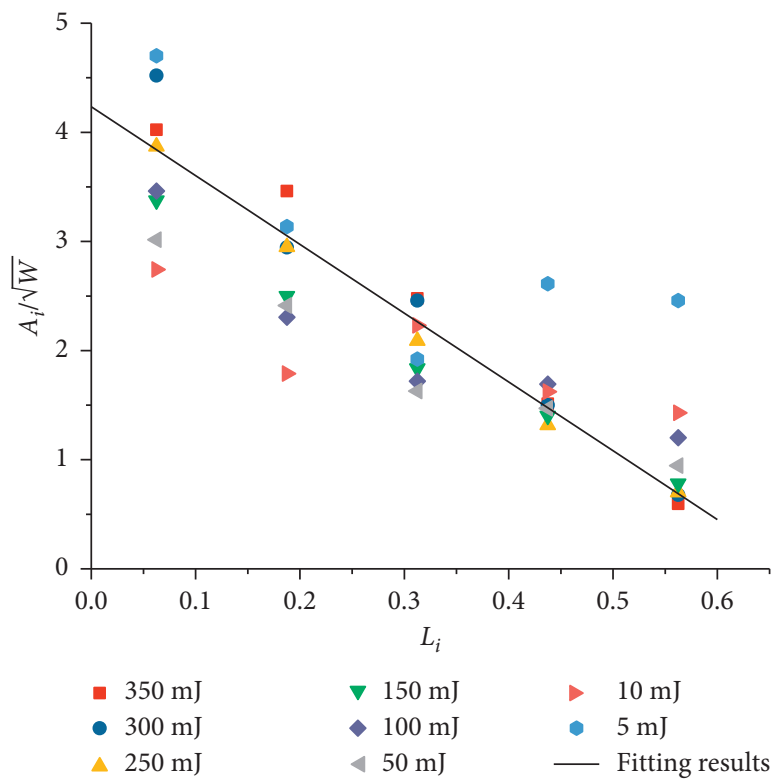

FIgURE 6: Attenuation of the maximum tensile displacement with distance to disturbance source.

digital images of the blocks during vertical disturbances, a digital image correlation and evaluation software computes the motion of each image point by comparing the digital images before and after deformation [25].

\section{Experimental Results}

3.1. Vertical Vibration. As shown in Figure 4, the vertical displacements of five rock blocks were obtained by using DIC method. After the disturbance load was applied, the vertical vibration of the blocky system consisted of two phases [1]: the forced vibration phase and the free vibration phase. Compression displacements were observed in the forced vibration phase. When the disturbance load ended, there should be a remarkable tensile displacement in the free vibration phase. Vertical vibration gradually stopped with the dissipation of energies.

With the increase of disturbance energies, the amplitudes of the vertical displacements significantly increased. The blocky system entered a quasi-resonance operating 


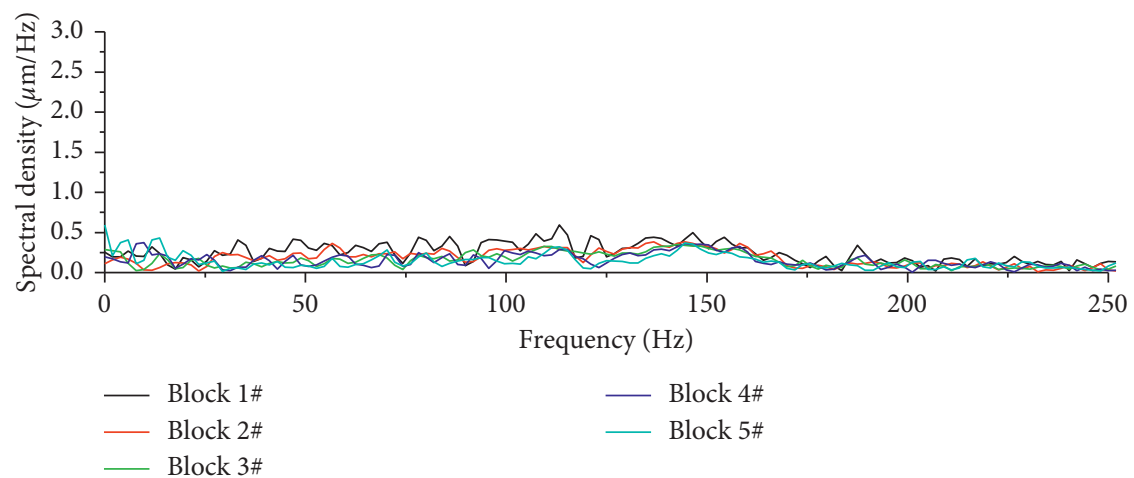

(a)

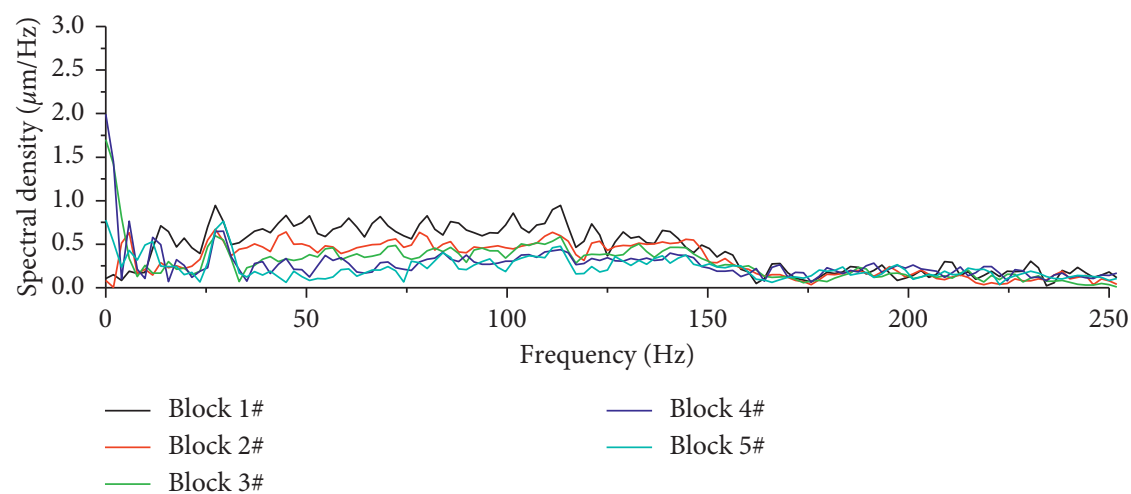

(b)

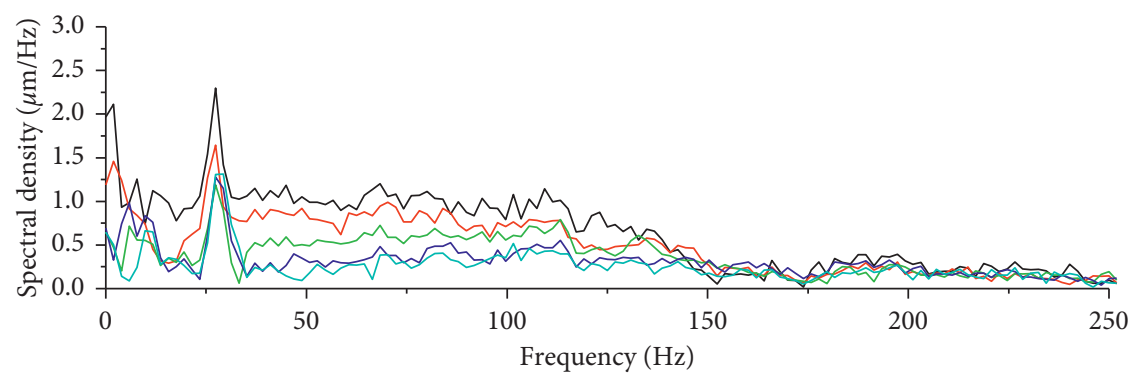

— Block 1\# — Block 4\#

— Block 2\#

Block 5\#

- Block 3\#

(c)

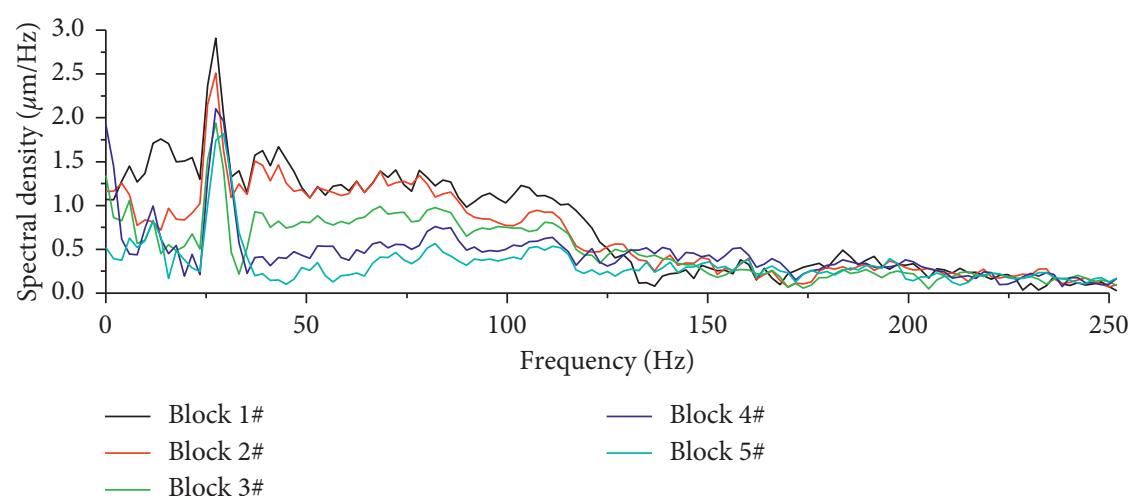

(d)

Figure 7: Spectral density of vertical displacement with different disturbance energies: (a) $50 \mathrm{~mJ}$; (b) $150 \mathrm{~mJ}$; (c) $250 \mathrm{~mJ}$; (d) $300 \mathrm{~mJ}$. 


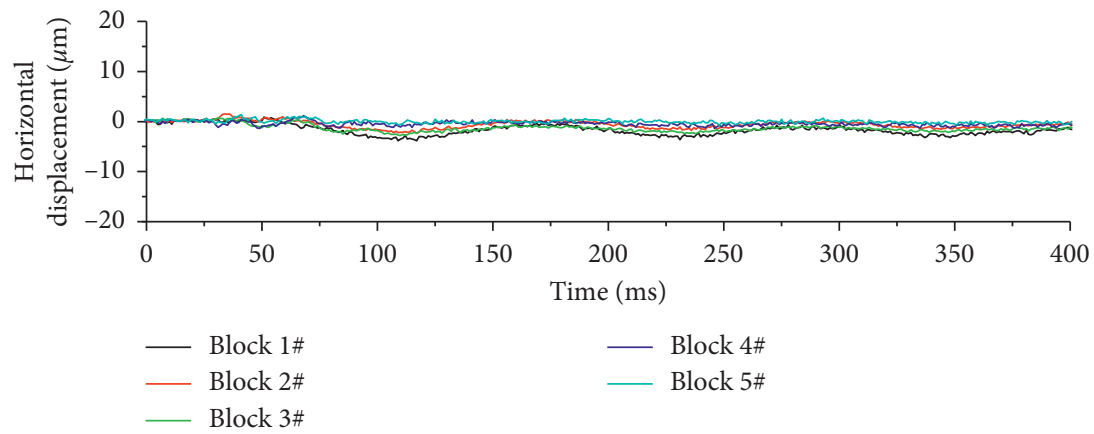

(a)

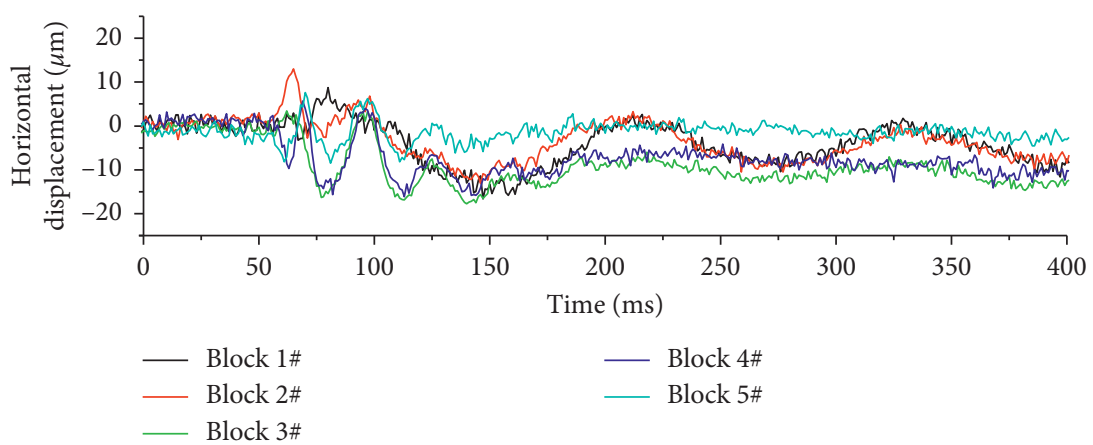

(b)

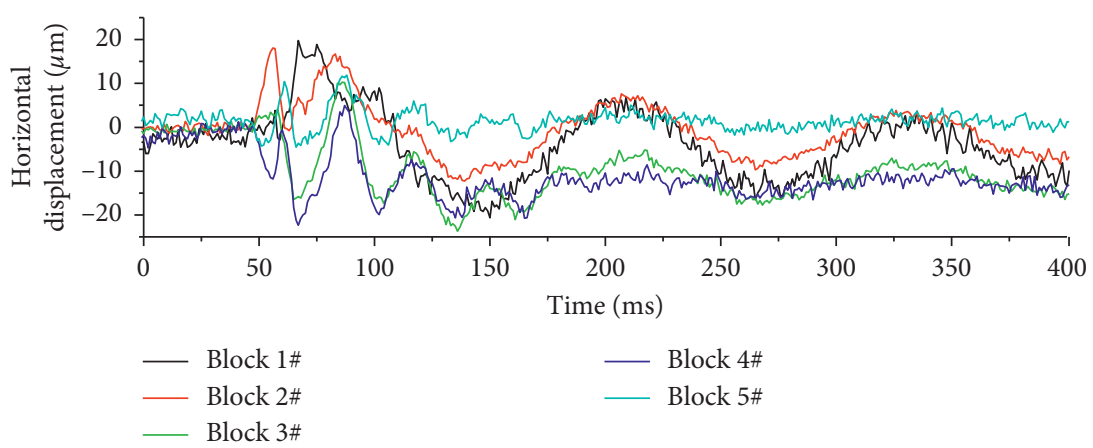

(c)

FIGURE 8: Horizontal displacements of rock blocks with different disturbance energies: (a) $150 \mathrm{~mJ}$; (b) $250 \mathrm{~mJ}$; (c) $350 \mathrm{~mJ}$.

mode as a whole if the disturbance energies were large enough (see Figures 4(c) and 4(d)); in this state, the friction between adjacent blocks can be dramatically reduced or even completely disappeared [18]. Vertical vibration of the blocky system in quasi-resonance operating mode can last longer and will not immediately stop.

As plotted in Figure 5, the relations between the maximum tensile displacements and disturbance energies can be expressed as

$$
\begin{aligned}
A_{i} & =k_{i} \sqrt{W}, \\
k_{i} & =-0.788 i+4.628,
\end{aligned}
$$

where $A_{i}(i=1,2,3,4,5)$ is the maximum tensile displacements, $k_{i}(i=1,2,3,4,5)$ is the fitting coefficient, and $W$ is the disturbance energy.

From equation (3), the attenuation of $A_{i}$ with distance to disturbance source (the center point on the top surface of block 1\#) can be deduced as follows:

$$
\frac{A_{i}}{\sqrt{W}}=-0.788 \frac{L_{i}}{h}+4.234
$$

where $h=0.125 \mathrm{~m}$ is the height of a single rock block and $L_{i}=(i-0.5) h$ is the distance to disturbance source. Figures 5 and 6 show that the fitting results of equations (3) and (4) match the experimental results well.

3.2. Fourier Frequency Spectrum of Vertical Displacement. The Fourier frequency spectra of vertical displacement are plotted in Figure 7. Frequency spectral density of block 1\# had a wide distribution, and more high-frequency waves were included in the wave packets of block 1\#. These highfrequency waves attenuated significantly with increase in the distance to disturbance source. In blocks $4 \#$ and 5\#, the majority was the low-frequency waves. It meant that, in the process of stress wave propagation in the blocky rock system, the vibration in the loading direction tended to transfer from 


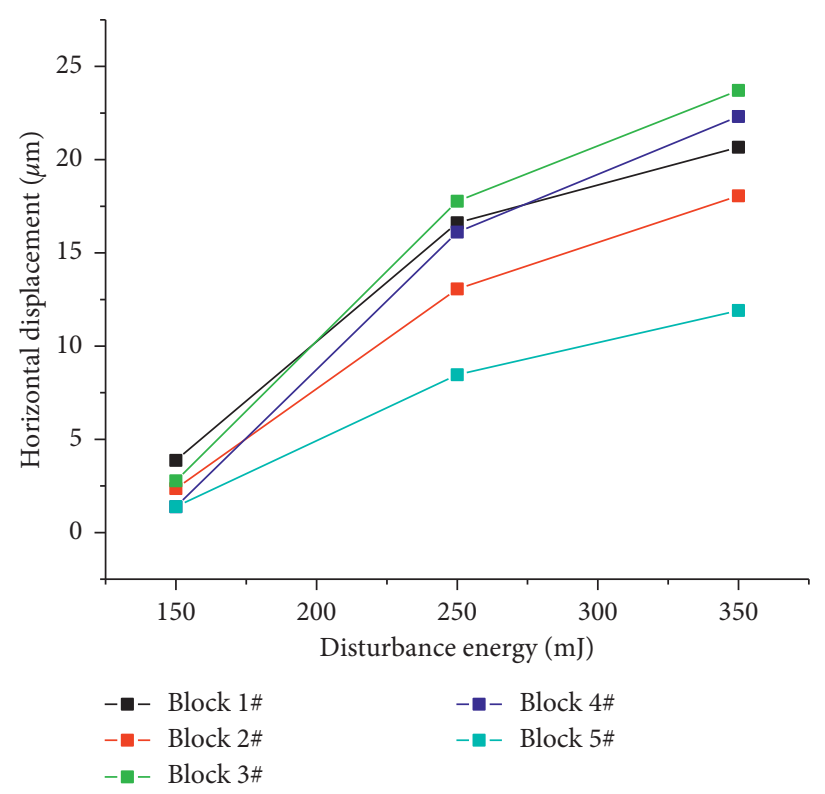

FIgURE 9: Maximum horizontal displacements of rock blocks.

high frequency to low frequency. Figure 7 also shows that, with the increase of disturbance energies, the local maximum frequencies of vertical displacements will not change and only the amplitude frequency increases. Thus, disturbance energies cannot change the modes of stress wave propagation. The propagation modes only depend on the structural characteristics of the blocky rock system.

3.3. Horizontal Motions. As plotted in Figure 8, horizontal displacements were observed, which were mainly due to the translational and rotational motions of rock blocks. When $W=150 \mathrm{~mJ}$, the horizontal displacements were negligible (see Figure $8(\mathrm{a})$ ). When $W=350 \mathrm{~mJ}$, the horizontal displacements could reach a maximum value of $23.71 \mu \mathrm{m}$ (see Figure 8(c)). As $W$ increased, the translational and rotational motions became more significant. The amplitudes of horizontal displacements attenuated from block $1 \#$ to $5 \#$ with the increase in distance to disturbance source.

The interfaces of the rock blocks are not absolutely flat. The slight fluctuations of the interfaces may cause initial shear force, which is less than the friction force when no disturbance load is applied. Under the disturbance load, if disturbance energies are large enough, the vertical tensile displacements may significantly reduce the maximum static friction force. If the maximum static friction force is lower than the initial shear force, the translational and rotational motions of rock blocks take place and will last for quite a long time, relative to the loading time (see Figure 3). Maximum horizontal displacements of rock blocks are shown in Figure 9, which can reflect the degree of friction reduction. As the disturbance energies increase, it is obvious that the low friction effect becomes more significant.
3.4. Reduced Friction Force. To estimate the reduced friction force, the blocky rock system is simplified into a multipledegree-of-freedom mass-spring-dashpot system [1]. Based on such a consideration, the nonlinear mechanical behavior of adjacent rock blocks can be simulated with a Kelvin-Voigt model. Assume that the relationship between the reduced friction force and the maximum tensile displacement is

$$
\Delta N_{i}=k_{0} A_{i}
$$

where $k_{0}$ is an equivalent spring coefficient and depends on inherent properties of the contact surfaces. From equations (3)-(5), the reduced friction force can be expressed as

$$
\Delta F_{i}=\mu \Delta N_{i}=\mu k_{0} A_{i}=\mu k_{0} \sqrt{W}\left(4.234-0.788 \frac{L_{i}}{h}\right) .
$$

The horizontal motions depend on the equilibrium of the shear force $T_{i}$ and friction force $F_{i}$. Before the disturbance load, $T_{i} \leq F_{i}$, and the blocky rock system is stable. After the impact load is applied, the tensile displacements of adjacent rock blocks lead to friction reduction. Once the condition of $T_{i}>F_{i}-\Delta F_{i}$ is met, the block starts to slip horizontally. The shear motions of blocks can reduce friction coefficient $\mu$, which causes a further reduction of friction forces and finally leads to geological disasters of different scales.

\section{Discussion}

As analyzed above, the critical condition for rock blocks to start a horizontal motion can be expressed as $T_{i}=F_{i}-\Delta F_{i}$. The critical disturbance energy can be easily derived from equations (3) and (6) as follows:

$$
W=\left(\frac{k^{\prime} x_{c}}{\mu k_{0} k_{i}}\right)^{2}(1-\beta)^{2},
$$


where $k^{\prime}$ and $x_{c}$ are the elastic coefficient and critical displacement of friction constitutive curves, respectively. $F_{i}=$ $k^{\prime} x_{c}$ is the shear strength. $\beta$ is the ratio of shear force to shear strength, $\beta=T_{i} / F_{i}$. Obviously, $0 \leq \beta \leq 1$.

Equation (7) shows the dependence of the disturbance energy on the initial stress state. It is noteworthy that when $\beta \longrightarrow 1, W \longrightarrow 0$. This means even a slight disturbance may make the horizontal motions happen, which may lead to geological disasters with great energy release. Triggering mechanism of geological disasters is clear. External disturbances cause tensile displacements of adjacent rock blocks, which reduces the normal stress and friction force of the contact surfaces. In the subcritical state $(\beta \longrightarrow 1)$, friction force reduction can easily break the equilibrium of forces along the contact surface. The mechanism can explain the remotely triggered earthquake [26], which can be considered as a larger-scale slip motion than a rock burst in a tunnel.

Besides the impact loads, the anomalously low friction phenomena can also be induced by ocean tides [27] or hydraulic fracturing [28]. Elevated pore pressures reduce the effective stress of contact surfaces, which causes the friction reduction. In addition, there may be a cumulative weakening effect on the friction coefficient as the external disturbances occur frequently.

\section{Conclusions}

Based on the structural hierarchy theory, rock masses can be regarded as a blocky rock system. When a disturbance load is applied, anomalously low friction phenomenon may take place and cause geological disasters. To investigate the anomalously low friction phenomena, a series of impact experiments on granite blocks were conducted by using an electrodynamic vibration exciter and a digital image correlation (DIC) method based on high-speed photography.

With the increase of disturbance energies, the amplitudes of the vertical displacements significantly increased, and the tensile phases of vertical vibration may reduce the maximum static friction force, namely, the shear strength. The blocky system entered a quasi-resonance operating mode as a whole if the disturbance energies were large enough. In the process of stress wave propagation in the blocky rock system, the vibration in the loading direction tends to transfer from high frequency to low frequency, and the modes of stress wave propagation do not correlate very much with disturbance energies. The observed translational and rotational motions were due to the initial shear force, which is locked by the friction force when no disturbance load is applied. External disturbances reduce the friction force and weaken the constraint. This causes the horizontal motions of the work block. The low friction effect becomes more significant with larger disturbance energies.

Stability of the blocky rock system is very sensitive to the initial stress state. External disturbances cause tensile displacements of adjacent rock blocks, which reduces the normal stress and friction force of the contact surfaces. In the subcritical state, friction force reduction can easily break the equilibrium of forces along the contact surface and even a slight disturbance may make the horizontal motions happen, which may lead to geological disasters with great energy release.

\section{Data Availability}

The experimental data used to support the findings of this study are available from the corresponding author upon request.

\section{Conflicts of Interest}

The authors declare that they have no conflicts of interest.

\section{Acknowledgments}

The present study was supported by the Opening Project of Tunnel and Underground Engineering Research Center of Jiangsu Province (TERC). The authors also acknowledge the financial support of the National Natural Science Foundation of China (Grant no. 51909120).

\section{References}

[1] G. W. Ma, X. M. An, and M. Y. Wang, "Analytical study of dynamic friction mechanism in blocky rock systems," International Journal of Rock Mechanics and Mining Sciences, vol. 46, no. 5, pp. 946-951, 2009.

[2] L. Li, W. Li, J. Tang, and J. Lv, "Influence of bidirectional impact loading on anomalously low-friction effect in block rock media," Advances in Civil Engineering, vol. 2018, Article ID 9156304, 9 pages, 2018.

[3] V. V. Adushkin and A. A. Spivak, Geomechanics of Large-Scale Explosions, Nedra Publishers, Moscow, Russian, 1993.

[4] S. K. Guha, Induced Earthquakes, Springer Science \& Business Media, Berlin, Germany, 2013, https://books.google.com/books? $\mathrm{hl}=$ zh-CN\&lr=\&id=IW4yBwAAQBAJ\&oi=fnd\&pg=PP12\&dq= Induced+Earthquakes+guha\&ots=RrCLt_DYQ-\&sig $=4 \mathrm{RYZyDE}$ YdYCXuFSNREakma79Yv8.

[5] K. Sarkarinejad and B. Zafarmand, "Stress state and movement potential of the Kar-e-Bas fault zone, Fars, Iran," Journal of Geophysics and Engineering, vol. 14, no. 4, pp. 998-1009, 2017.

[6] F. Meng, H. Zhou, Z. Wang et al., "Experimental study of factors affecting fault slip rockbursts in deeply buried hard rock tunnels," Bulletin of Engineering Geology and the Environment, vol. 76, no. 3, pp. 1167-1182, 2017.

[7] H. Zhou, F. Meng, C. Zhang, D. Hu, F. Yang, and J. Lu, "Analysis of rockburst mechanisms induced by structural planes in deep tunnels," Bulletin of Engineering Geology and the Environment, vol. 74, no. 4, pp. 1435-1451, 2015.

[8] J. Pan, S. Liu, S. Wang, and Y. Xia, "A new theoretical view of rockburst and its engineering application," Advances in Civil Engineering, vol. 2018, Article ID 4683457, 12 pages, 2018.

[9] M. A. Sadovskiy, "Natural lumpiness of rocks," Doklady Akademii Nauk SSSR, vol. 247, no. 4, pp. 829-831, 1979.

[10] M. V. Kurlenya, V. N. Oparin, and A. A. Eremenko, "Relation of linear block dimensions of rock to crack opening in the structural hierarchy of masses," Journal of Mining Science, vol. 29, no. 3, pp. 197-203, 1993.

[11] C.-Z. Qi, Q.-H. Qian, M.-Y. Wang, and J. Dong, "Structural hierarchy of rock masses and mechanism of its formation," 
Journal of Rock Mechanics and Geotechnical Engineering, vol. 24, pp. 2838-2846, 2005.

[12] L.-T. Xie, P. Yan, W.-B. Lu, M. Chen, and G.-H. Wang, "Effects of strain energy adjustment: a case study of rock failure modes during deep tunnel excavation with different methods," KSCE Journal of Civil Engineering, vol. 22, no. 10, pp. 4143-4154, 2018.

[13] P. Yan, Z. Zhao, W. Lu, Y. Fan, X. Chen, and Z. Shan, "Mitigation of rock burst events by blasting techniques during deep-tunnel excavation," Engineering Geology, vol. 188, pp. 126-136, 2015.

[14] T. Liu, H. Wang, X. Su, K. Li, S. Liu, and F. Guo, "Instability mechanism of cavity-bearing formation under tunnel excavation disturbance," Advances in Civil Engineering, vol. 2020, Article ID 9038421, 15 pages, 2020.

[15] A. Demirci, S. Özden, T. Bekler, D. Kalafat, and A. Pınar, "An active extensional deformation example: 19 may 2011 Simav earthquake $(M w=5.8)$, Western Anatolia, Turkey," Journal of Geophysics and Engineering, vol. 12, no. 4, pp. 552-565, 2015.

[16] G. Papathanassiou, S. Valkaniotis, A. Ganas, N. Grendas, and E. Kollia, "The november 17th, 2015 Lefkada (Greece) strikeslip earthquake: field mapping of generated failures and assessment of macroseismic intensity ESI-07," Engineering Geology, vol. 220, pp. 13-30, 2017.

[17] N. I. Aleksandrova, "Pendulum waves on the surface of block rock mass under dynamic impact," Journal of Mining Science, vol. 53, no. 1, pp. 59-64, 2017.

[18] M. V. Kurlenya, V. N. Oparin, and V. I. Vostrikov, "Pendulum-type waves. Part II: experimental methods and main results of physical modeling," Journal of Mining Science, vol. 32, no. 4, pp. 245-273, 1996.

[19] M. V. Kurlenya, V. N. Oparin, and V. I. Vostrikov, "Anomalously low friction in block media," Journal of Mining Science, vol. 33, no. 1, pp. 1-11, 1997.

[20] M. V. Kurlenya, V. N. Oparin, and V. I. Vostrikov, "Effect of anomalously low friction in block media," Journal of Applied Mechanics and Technical Physics, vol. 40, no. 6, pp. 1116-1120, 1999.

[21] G. G. Kocharyan, A. A. Kulyukin, V. K. Markov, D. V. Markov, and D. V. Pavlov, "Small disturbances and stress-strain state of the Earth's crust," Physical Mesomechanics, vol. 8, no. 1-2, pp. 21-33, 2005.

[22] N. I. Aleksandrova, A. G. Chernikov, and E. N. Sher, "Experimental investigation into the one-dimensional calculated model of wave propagation in block medium," Journal of Mining Science, vol. 41, no. 3, pp. 232-239, 2005.

[23] Y. Seo, G. R. Chehab, and Y. R. Kim, "Post-peak characterization of asphalt concrete using DIC method," KSCE Journal of Civil Engineering, vol. 10, pp. 1-7, 2006.

[24] H. Wu, G. Zhao, W. Liang, E. Wang, and S. Ma, "Experimental investigation on fracture evolution in sandstone containing an intersecting hole under compression using DIC technique," Advances in Civil Engineering, vol. 2019, Article ID 3561395, 12 pages, 2019.

[25] B. Pan, K. Qian, H. Xie, and A. Asundi, "Two-dimensional digital image correlation for in-plane displacement and strain measurement: a review," Measurement Science and Technology, vol. 20, no. 6, Article ID 062001, 2009.

[26] D. P. Hill, P. A. Reasenberg, A. Michael et al., "Seismicity remotely triggered by the magnitude 7.3 Landers, California, earthquake," Science, vol. 260, no. 5114, pp. 1617-1623, 1993.
[27] H. Houston, "Low friction and fault weakening revealed by rising sensitivity of tremor to tidal stress," Nature Geoscience, vol. 8, no. 5, pp. 409-415, 2015.

[28] L. W. Shen, D. R. Schmitt, and R. Schultz, "Frictional stabilities on induced earthquake fault planes at fox Creek, Alberta: a pore fluid pressure dilemma," Geophysical Research Letters, vol. 46, no. 15, pp. 8753-8762, 2019. 